\title{
Monitoring and Evaluation in South-South Cooperation: The Case of CPEC in Pakistan
}

\author{
Murad Aliఠ
}

\subsection{INTRODUCTION}

Among the six economic corridors envisaged under the BRI, CPEC is the only corridor that is already in the implementation phase, as work on a number of multi-sector infrastructure projects is already in progress. With a portfolio of about $\$ 62$ billion for the 2015-2030 period, the leadership in both China and Pakistan has significant expectations for CPEC. In just a short time, the corridor has transformed the bilateral ties between the two countries. These ties have been cordial in the past but have been limited mainly to mutual cooperation in the areas of defence and security (Ali, 2017). Since the commencement of CPEC, the China-Pakistan relationship has expanded into a multi-dimensional partnership. Regular visits and meetings take place between the delegates of both countries. These meetings are not limited to political representatives and government officials-stakeholders from academia, business, think tanks, and the media also interact regularly. If successfully implemented and utilised, CPEC is expected to significantly enhance regional connectivity and trade and could facilitate the inter-regional movement of people, goods, and services.

The chapter examines the development partnership between both governments under CPEC to explore whether the official narrative of SSC is practised on the ground. It investigates whether SSC principles and features that China is advocating are being upheld while implementing projects in Pakistan. The chapter begins with an overview of CPEC and its potential contribution to the

M. Ali $(\bowtie)$

Department of Political Science, University of Malakand, Chakdara, Pakistan

(C) The Author(s) 2021

S. Chaturvedi et al. (eds.), The Palgrave Handbook of Development

Cooperation for Achieving the 2030 Agenda, https://doi.org/10.1007/978-3-030-57938-8_13 
2030 Agenda for Sustainable Development and the Sustainable Development Goals (SDGs) in Pakistan. A description of the analytical framework and its appropriateness to assess the quality of SSC constitutes the subsequent parts of the discussion. Based on the research findings, the chapter then discusses CPEC in the light of the five dimensions and 20 indicators that form the core of the SSC framework.

\subsection{CPEC: A CATAlyst FOR THE 2030 AgENDA AND SDGs IN PAKISTAN?}

While the world has embraced the 2030 Agenda and the 17 SDGs, finding financial means to attain these goals remains an uphill task. Most countries, particularly those in the Global South, are faced with numerous challenges, and it is beyond their individual capacities to implement the 2030 Agenda without external financing. It is estimated that an aggregate of $\$ 3.3-\$ 4.5$ trillion is needed annually to implement the 2030 Agenda globally (World Bank, 2015). Although there are multiple sources of external financing that developing countries have access to, still "the annual SDG financing gap in developing countries is estimated at approximately $\$ 2.5$ trillion" (Organisation for Economic Co-operation and Development [OECD], 2016, p. 69). The Addis Ababa Action Agenda has identified foreign direct investment (FDI) as an essential source to complement national development efforts (United Nations General Assembly [UNGA], 2015). It is argued that "investments in developing countries - and even in the least developed countries - are seen as business opportunities [...] companies provide jobs, infrastructure, innovation and social services" (OECD, 2016, p. 17).

In view of the strong link between external financing and its potential to contribute to socio-economic development, there are significant prospects associated with Chinese SSC in the form of CPEC in Pakistan. Three main components of CPEC are investments in the energy sector ( $\$ 35$ billion) as well as in communication infrastructure and special economic zones (SEZs) (\$11 billion). Substantial investments in these areas have the potential to promote three SDGs, including Goals 7, 8, and 9. These three SDGs ensure access to affordable, reliable, sustainable, and modern energy for all (Goal 7), promote sustained, inclusive, and sustainable economic growth, full and productive employment, and decent work for all (Goal 8), and focus on building resilient infrastructure, promoting inclusive and sustainable industrialisation, and fostering innovation (Goal 9) (UNGA, 2015, p. 14). Thus, the execution of CPEC is expected to directly contribute towards attaining these three SDGs. If externalities regarding social and environmental costs are effectively addressed, Pakistan expects that CPEC will help in resolving the chronic issue of energy shortfalls, and people will have access to reliable and sustainable energy. Similarly, with the creations of SEZs, people will have better job opportunities and means of earning their livelihoods. With investments in the communication 
infrastructure, people are expected to have access to better roads and transport facilities. In sum, these three SDGs are directly related to CPEC projects, and Pakistan could significantly move ahead on these selected SDGs if various ventures planned under the corridor are successfully implemented.

Alongside contributing towards promoting the above SDGs directly, CPEC-related investments are likely to help in achieving various SDGs indirectly. For example, Goal 1 states to "end poverty in all its forms everywhere" (UNGA, 2015, p. 14). CPEC projects have created "more than 30,000 direct jobs for Pakistanis" (Government of Pakistan, 2018, p. 186), and the government estimates that it would generate two million jobs in the long run. This means if two million people secure employment, two million families will have a better means of livelihood and, subsequently, will achieve food security (Goal 2) as well as will have access to better health services (Goal 3), quality education (Goal 4), and clean water and sanitation (Goal 6). In sum, the effective execution of CPEC has enormous potential to contribute towards achieving a number of SDGs in Pakistan.

\subsection{Analytical Framework for Assessing CPEC}

The development partnership between Pakistan and China presents a compelling case to analyse the Chinese approach to SSC in Pakistan. China's modus operandi of project selection and execution is evaluated through an analytical framework developed by NeST. As presented in Table 13.1, the framework has five broad dimensions for assessing the effectiveness of SSC. It merits a mention here that the key themes identified in the SSC framework are largely the ones Beijing has endorsed in its official documents pertaining to foreign aid. As SSC is mostly dominated by government-to-government agreements with limited transparency, an assessment of China as the largest SSC provider is a very insightful case in the broader context of SSC. The aim is to critically evaluate Chinese-funded interventions in Pakistan and assess to what extent key features of SSC are actually adhered to. In analysing Chinese assistance to Pakistan, this chapter has two broad objectives. The first is to contribute to debates on the significance of SSC in the 2030 Agenda and its role in financing regional infrastructure projects. Second, by applying appropriate monitoring and evaluation (M\&E) systems for SSC in the context of Pakistan, it is among a handful of research studies on this subject. The findings are of great significance to further refine and improve the analytical instruments for evaluating development cooperation between SSC actors. Also, the findings and lessons learnt are of equal importance for academics, researchers, practitioners, and policy-makers in the field of aid and development effectiveness, which is a critical area for the implementation of the 2030 Agenda.

The analytical framework consists of five dimensions and 20 indicators. The first element is inclusive national ownership, comprising four indicators. As SSC is mostly considered to be based on government-to-government 


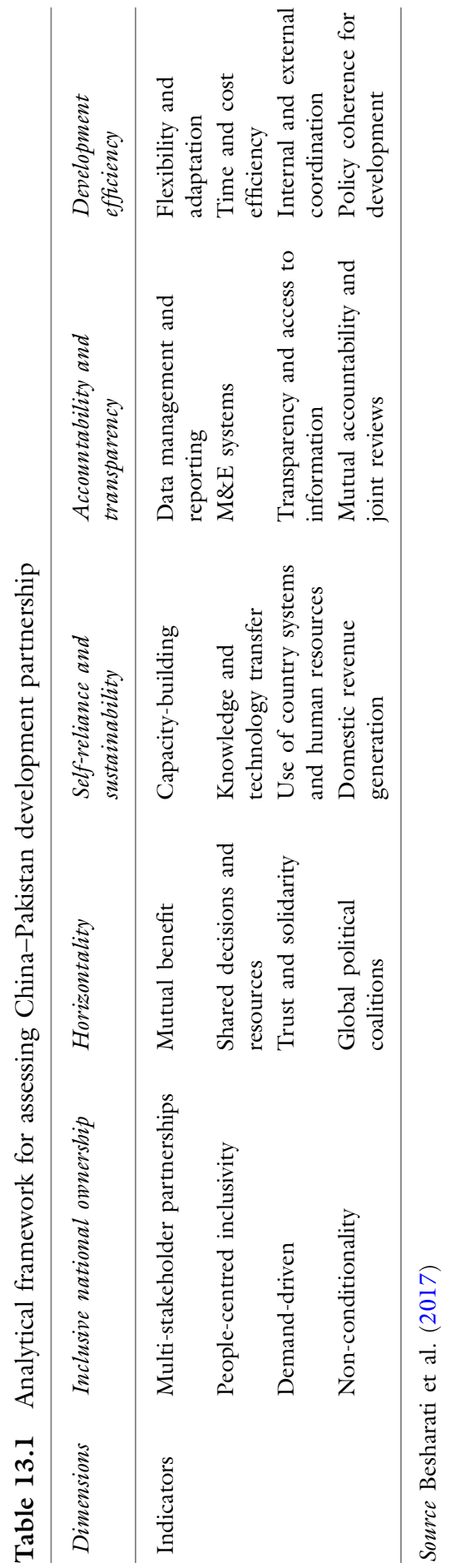


relations, the framework stresses inclusive participation involving various stakeholders, including non-state actors and civil society organisations. Similarly, it focusses on people-centred inclusivity, which implies that SSC activities help in improving the socio-economic status of the poorest and most disenfranchised populations. The second aspect of the framework is horizontality, as SSC is considered to be a development partnership between equal partners. It means that instead of donors and recipients per se, SSC is for mutual benefit. Joint decision-making processes and mechanisms for sharing resources are among its key features. The third dimension is self-reliance and sustainability, which implies that SSC should aim to reduce external dependency. It can be achieved by various means, such as consistently enhancing and improving local capacity via the transfer of relevant knowledge and technology. The fourth element of the analytical framework is that SSC should be characterised by accountability and transparency. It elaborates that there must be sufficient data management and reporting systems. Also, there must be effective and quality M\&E systems and tools so that various phases of the project cycle are properly evaluated against the project goals and targets. The fifth and last dimension of the framework is about the overall efficiency or impact of SSC endeavours in reaching the intended development targets.

The framework is very useful, as it has not only enshrined the key principles with which to evaluate the effectiveness of SSC, but the selected dimensions and respective indicators are also closely related to the main features advocated by Beijing in its foreign aid policy documents. However, the framework has its own limitations. By and large, the five dimensions resemble the discourse on aid effectiveness principles led by the Development Assistance Committee (DAC) of the Organisation for Economic Co-operation and Development (OECD). There is still no unanimous intergovernmental consensus among Southern aid providers on the use of such frameworks for assessing the impact of SSC. Besides, some of the indicators, such as "trust and solidarity", "global political coalitions", and "flexibility and adaptation", are quite broad concepts open to various interpretations. Hence, there is a need for further elaboration and refinement of the indicators regarding how these principles can be measured and used to assess the value of SSC. Despite these limitations, the framework is helpful, as it provides an effective and appropriate set of dimensions and principles with which to evaluate the quality of SSC.

There is another peculiar characteristic of the analytical framework: The five broad dimensions enshrined in the SSC framework are more or less the same as those that China has officially endorsed in its policy documents on foreign aid, with the exception of accountability and transparency. As per policy documents, China has vowed to adhere to such principles in the allocation of development cooperation. Beijing clearly mentions peaceful co-existence, respect for sovereignty, and mutual benefit as its guiding doctrines. Similarly, values such as mutual respect, equality, fulfilling promises, building local capacity, addressing the actual needs of partner countries, and adaptation and flexibility in development cooperation policy are some of the stated principles 
and features of development finance provided by China (People's Republic of China, 2014). Therefore, "while discussions around defining, accounting and reporting SSC flows are still inconclusive and present a vast diversity of views and approaches" (Besharati et al., 2017, p. 5), the analytical framework provides an appropriate set of indicators on which the quality and effectiveness of SSC partnerships can be measured.

\subsection{CPEC IN THE SSC FRAMEWORK: Findings AND Discussion}

As illustrated earlier, the analytical framework has five broad dimensions with 20 indicators. The following section discusses CPEC in the SSC framework in detail.

\subsubsection{Inclusive National Ownership and CPEC}

To assess the quality and effectiveness of SSC, the first aspect is inclusive national ownership. Rather than simply a state-to-state or government-togovernment partnership, SSC initiatives should have policy frameworks and institutional mechanisms that involve various state and non-state actors to ensure the inclusive participation of a broad range of stakeholders (Indicator 1). When exploring which kinds of mechanisms and processes are in place to enable the participation of multiple stakeholders in CPEC projects, in the case of Pakistan, a number of stakeholders are involved in the identification, prioritisation, and recommendation of projects that are funded under CPEC. At the top, there is the Joint Cooperation Committee (JCC), co-chaired by the minister of Planning Development Reform (PDR) from the Pakistani side and the vice-chairman of the National Development and Reform Commission (NDRC) from the Chinese side. The JCC is the highest body, where all projects are discussed, reviewed, and approved. It comprises both political figures and administrative officials, such as heads of different departments and experts from various fields. Under the JCC, there are five joint working groups (JWGs), comprising experts from government agencies of both countries. Thus, at these two tiers, both Chinese and Pakistani officials are involved.

Within Pakistan, there are several actors involved in CPEC at various levels. First, projects are included in CPEC because of the financial and technical need, and all such projects are selected via existing government decisionmaking processes (personal communication with deputy director of CPEC, September 2017). The deputy director further stated that the Economic Coordination Committee, the Executive Committee of the National Economic Council, and the Central Development Working Party as well as other approving bodies and relevant ministries are involved in the identification and recommendation of projects to the JCC. Also, there is the CPEC Cabinet Committee, headed by the prime minister, comprising several ministers and secretaries/heads of key ministries engaged in CPEC projects. In addition, 
there is a Parliamentary Committee on CPEC comprising members from the ruling party as well as various opposition parties. In addition, there is a High-Powered Interprovincial Committee headed by the prime minister, with representation from all provinces and the federation. Thus, various national stakeholders and policy-making institutions are involved to ensure inclusive national ownership. ${ }^{1}$

Another indicator of the SSC framework is people-centred inclusivity (Indicator 2), which implies that SSC activities need to benefit the poorest and less advantaged people and that both SSC actors follow the "labour, land, safety, environmental and social standards of both partner countries" (Besharati et al., 2017 , p. 13). Because about 75 per cent of CPEC's funding portfolio is for energy projects, access to an uninterrupted power supply could greatly benefit common people. An official in the Ministry of PDR stated that various roads planned under CPEC would enhance interprovincial connectivity and connect the less-developed areas of Baluchistan, Khyber Pakhtunkhwa, and Azad Jammu and Kashmir with the main corridor and help in bringing a new era of development to these parts (personal communication, September 2017). Similarly, almost all provinces have energy projects and industrial zones under CPEC. Hence, in terms of people-centred inclusivity, the expected socioeconomic benefits would not be concentrated on certain groups of people or geographical areas, but would reach diverse segments of the population.

Regarding the protection of people and the environment, there are concerns about $\mathrm{CO}_{2}$ emissions associated with coal-based thermal-power projects. Both Pakistani and Chinese officials stated during interviews that they have committed to adopt clean-coal combustion technologies that conform to international standards. Chinese deputy chief of mission in Pakistan stated that they are bringing to Pakistan the latest supercritical technology, which is used elsewhere in coal plants in the United States and Europe (personal communication, September 2017). Similarly, the deputy director of CPEC at the Ministry of PDR also asserted that Pakistan is conscious of the environmental repercussions of coal-based energy stations, and therefore consistent efforts are underway to minimise the costs to environment-the latest technology has been imported for coal power plants and offers reduced levels of $\mathrm{CO}_{2}$ and other gas emission (personal communication, September 2017).

However, while interacting with a number of academics and civil society representatives in Pakistan, genuine concerns were raised that coal-based power plants could have serious environmental implications. A researcher from an Islamabad-based think tank stated that coal-fired power plants will prove harmful to the environment in the long run, particularly in Punjab, as the province is an agricultural hub of the country (personal communication, September 2017). Thus, although there are high hopes associated with huge investments being made in the energy sector, a paradigm shift towards coal-fired power plants could have serious long-term environmental implications for Pakistan, which is already quite vulnerable to climate-induced hazards (Isran, 2017; Saleem, 2017a; Zaman, 2016). According to the Global 
Climate Risk Index 2017, which ranks countries based on impacts of extreme weather events, both in terms of fatalities as well as economic losses, Pakistan is among the 10 most-affected countries (Kreft et al., 2017). Greater dependence on coal-based power plants could further increase its vulnerability to environmental risks.

The element of inclusive national ownership also focusses on the demanddriven nature of the SSC, which asserts that SSC initiatives need to be clearly aligned to the needs and national priorities of partner countries (Indicator $3)$. In CPEC, the demand-driven nature of Chinese investment and cooperation is evident from the target sectors. For instance, investments in the energy sector are one of the main components of CPEC, as about 75 per cent of the investments are being made in power projects. This is due to the fact that Pakistan has been suffering from an acute energy shortfall. During times of acute need, particularly in the summer, the shortfall in energy reaches 7000 megawatts (MW), which "intensifies the woes of consumers, disrupts industrial and agricultural production and adds to costs making Pakistani products uncompetitive internationally" (Government of Pakistan, 2014, p. 16). According to policy documents, energy deficiency has a detrimental effect on the economy, causing an estimated 4-7 per cent loss to the country's gross domestic product (GDP) (Government of Pakistan, 2014).

In view of this, investments in the energy sector are a major component of CPEC. A total of 21 projects have been identified and planned in the energy sector, with a cost of more than $\$ 35$ billion and having the capacity to generate 17,045 MW (CPEC Secretariat, 2017). Regarding the modus operandi of identifying energy and other infrastructure projects, the deputy director in the CPEC Secretariat stated that all Chinese assistance is demanddriven, as either the federal or provincial government identifies projects, which are then discussed as per existing procedures at different levels. After internal discussions, the projects are sent to the JCC, which decides whether to finance it under CPEC or not (personal communication, September 2017). Hence, as per government officials, it seems that all CPEC-related projects are demand-driven, whether they are in the energy sector or infrastructure.

In relation to Indicator 4 of this SSC principle-dealing with nonconditionality - there are some concerns in Pakistan. For example, a researcher from an Islamabad-based think tank stated that Chinese investment has a very high rate of return, up to 17 per cent, and CPEC is going to become a debt trap for the country (personal communication, September 2017). There is also a perception that Pakistan could be in serious financial trouble when it comes to the outflow of loan payments along with payable interest and profit remittances to Chinese companies. Hence, various economists and analysts have argued that this would put immense pressure on Pakistan's foreign reserves in the future once the repayment period begins (Ahmad, 2017; Isran, 2017; Saleem, 2017b). Some critics even argue that it is the colonisation of Pakistan by China, as CPEC is a Chinese project, for Chinese interests, and Pakistan just happens to be part of the geographical terrain (Khan and Hyder, 2017; Zaidi, 2017). 
In contrast to this narrative, officials in policy-making institutions argue that the repayment of loans and outward flows of FDI and remittances would not pose a big financial challenge. An official in the Ministry of PDR stated that the interest rate was 2 per cent and Pakistan could easily repay loans, as CPEC projects would significantly boost productivity in various sectors (personal communication, September 2017). The official explained that CPEC would generate significant revenues, as there would be uninterrupted electricity and power for industries, which, in return, would lead to enhanced exports. Similarly, it was pointed out that the modernisation of transport infrastructure would result in greater inter-regional trade as well as in the generation of revenues in the form of a toll tax. In sum, there are two somewhat contrasting perceptions about whether there is any explicit or implicit form of conditionality from the Chinese side and what the long-term financial implications of CPEC are for Pakistan.

\subsubsection{CPEC in the Context of Horizontality}

The second aspect of the SSC framework is horizontality, as development partnerships between Southern actors are considered to be a mutual alliance between equal partners. It suggests that rather than being for the benefit of aid donors and recipients per se, SSC is for mutual benefit (Indicator 5), and there are joint decision-making mechanisms and resources (Indicator 6). Other key features of SSC under this dimension are trust and solidarity (Indicator 7) and global political coalitions or international alliances at different fora (Indicator 8) where Southern partners have shared interests.

Viewing CPEC within these parameters, there is a consensus-not only between the governments of both countries but also the intelligentsia from both Pakistan and China-that the corridor is mutually beneficial. Regarding its potential to enhance trade and regional connectivity, officials from both countries have stated that CPEC offers a win-win situation. The corridor presents a very viable alternate land-and-sea route via Pakistan's Gwadar Port to western regions of China. Thus, it has a number of mutual benefits concerning increased trade and regional connectivity.

Another dimension of the SSC is shared decision-making mechanisms for implementing development interventions. As mentioned earlier, to promote the construction of CPEC-related projects in Pakistan, the two countries set up the JCC, which is co-chaired by the minister of PDR from the Pakistani side and the vice-chairman of the NDRC from the Chinese side. The JCC is the highest body comprising both political figures and officials, such as heads of different departments. Under the JCC, there are five joint working groups, comprising experts from both countries, dealing with long-term planning, energy, transport infrastructure, industrial cooperation/SEZs, and the Gwadar Port. The JCC secretariats are within the NDRC in China and the Ministry of PDR in Pakistan, respectively. The two secretariats are responsible for communicating and coordinating with the respective line ministries 
related to the construction of CPEC. Thus, there exists a proper joint decisionmaking mechanism, which provides a platform for policy-makers and other stakeholders from both countries to discuss all CPEC projects and related issues.

Trust, solidarity, and broader political alliances are other key elements of the SSC framework under the domain of horizontality. In the context of SSC, it denotes that Southern partners have solidarity based on "common interest, objectives and principles" (Besharati et al., 2017, p. 14). China and Pakistan have a number of interests, including security concerns vis-à-vis India, geographical proximity, the role played by Islamabad in breaking the isolation of China in the 1960s, as well as backing China on issues such as Taiwan, Tibet, and Xinjiang (Ali, 2017; Hussain, 2016). The two countries have been cooperating in the field of defence and security for decades and have developed an "unusual level of mutual trust" (Small, 2015, p. 44). Thus, as far as trust, solidarity, and political alliances are concerned, it continues to remain unprecedented at the state or government level.

\subsubsection{Elements of Self-Reliance and Sustainability in CPEC}

To assess CPEC in the SSC framework, the third aspect is self-reliance and sustainability, which can be achieved through various means such as by consistently enhancing and improving local capacity (Indicator 9) as well as via the transfer of relevant knowledge and technology (Indicator 10). For accomplishing long-term and sustainable development outcomes, principles such as the use of local systems and resources (Indicator 11) and taking initiatives that could assist in domestic revenue generation (Indicator 12) are considered vital for SSC effectiveness.

For capacity-building and the transfer of knowledge and technology, various initiatives have been undertaken. These include offering scholarships to Pakistani students for studying in China as well as short-term scholarships for learning the Chinese language in Pakistan in order to prepare a well-trained labour force to properly implement CPEC projects (personal communication with officials in the CPEC secretariat, September 2017). Besides scholarships offered by the government, there are also funding opportunities from other sources. For example, the China Road and Bridge Corporation (CRBC)—one of the four large-scale, state-owned companies in China-is also implementing construction projects in Pakistan. In consultation with the Higher Education Commission, which is Pakistan's premier education body, the CRBC offered 30 fully funded scholarships to Pakistani students to study for their master's degree at Southeast University, China. Similarly, various other companies and organisations involved in CPEC are stated to have contributed to various social programmes in respective locations (personal communication with deputy chief of mission, Embassy of China, September 2017). Thus, to some extent, CPEC projects have been contributing towards capacity-building and the transfer of skills and technology in different areas. 
In relation to the principle of untied aid, there has been a dominant perception that almost all procurement for CPEC projects is done from China. There has been criticism in the media that there is no competitive international bidding, as CPEC projects are implemented by Chinese companies without such bidding processes (Mustafa, 2018; Saleem, 2017b). A researcher in an Islamabad-based think tank stated that almost all the machinery and equipment employed in Pakistan has been brought from China, and that there has been no open bidding process (personal communication, September 2017). About 75 per cent of CPEC financing is in the form of FDI, loans obtained by Chinese companies from Chinese banks. According to Pakistani officials, these companies and investors are better placed to get the most relevant, affordable, and advanced technology for their projects (personal communication, September 2017). The fact remains that, in CPEC projects, almost all procurement has been done from China.

Another element of this dimension is the use of local systems and resources. In Pakistan, there are media reports that Chinese companies have been bringing most of the workforce from China rather than employing locals (Hussain, 2017; Saleem, 2017b). Among researchers that were interviewed in Islamabad, the prevailing perception is that China is bringing its own labour, and the use of Pakistani labour or other resources is minimal. In contradiction to this, Pakistani and Chinese officials have stated that thousands of locals have been employed in various projects, and that the local cement and construction industries have witnessed a significant boost on account of CPEC. An official at the CPEC secretariat stated that the ratio of Chinese nationals working in CPEC projects would be 20-30 per cent (personal communication, September 2017). Similarly, the senior vice-president of the Islamabad Chamber of Commerce \& Industry stated that the cost of unskilled or semiskilled labour is about $\$ 700$ per month in China and about $\$ 200-270$ in Pakistan, so it would not make sense for the Chinese to bring their own workers (personal communication, September 2017). The chairman of the Parliamentary Committee on CPEC was quoted in the media stating that, at present, about 9581 Chinese nationals are working on CPEC-related interventions, and around 10,000 are involved in non-CPEC projects (Haider, 2017). He explained that a total of about 20,000 Chinese are working as specialists and supervisors for all projects taking place with China's assistance, and he added that around 60,000 Pakistanis are working on CPEC projects. The deputy chief of mission at the Embassy of China in Islamabad stated that some elements have been spreading this misperception that China is coming up with its own workforce rather than giving opportunities to local people (personal communication, September 2017). He also questioned why China would bring its own labour, given that cheaper labour is available locally. The Chinese diplomat also stated that it would be illogical to bring raw materials or other resources that are already available in Pakistan. Thus, it seems to be an overstatement that Chinese companies are bringing their own workers and that there are few job opportunities for locals in CPEC projects. 
Another important aspect of the analytical framework is domestic revenue generation and how SSC endeavours contribute to it in partner countries. There are significant prospects associated with CPEC and its potential for revenue generation. An official in the Board of Investment stated that the toll income alone generated by the CPEC route is hoped to be three times the national budget of the country once it becomes fully functional by 2030 (Board of Investment, 2017). However, a researcher calculated the potential of the CPEC toll and found that it seems highly unlikely that it could generate about $\$ 135$ billion, an annual revenue stream that is two to three times the total CPEC portfolio (Khawar, 2017). Khawar argued that, based on China's total trade with Africa and the Middle East, if 30 per cent of it is diverted through the CPEC route, which is shorter than the current sea lane used by China for its exports and imports, Pakistan could generate an annual toll income of up to $\$ 4.8$ billion. It must be clarified that those calculations are based on tolls from Chinese containers only. In its long-term plan, detailed in "Pakistan Vision 2025", the country has identified regional connectivity as a key element (Government of Pakistan, 2014). The policy document specifically mentions CPEC playing a vital role in achieving the potential of regional connectivity and trade with member states of the South Asian Association for Regional Cooperation, the Association of Southeast Asian Nations (ASEAN), the Central Asia Regional Economic Cooperation, and the Economic Cooperation Organization. A UN report has also stated that economic benefits of the corridor will go beyond participating countries and "will also benefit several neighbouring landlocked economies via access to sea through Pakistan" (United Nations Economic and Social Commission for Asia and the Pacific, 2017 , p. 9). In that case, there is a significant potential for increased revenue generation in the form of tolls and other means of domestic financing once the corridor is fully operational and utilised to its true potential to connect various countries of the region.

\subsubsection{Accountability and Transparency in CPEC Projects}

The fourth aspect of the analytical framework in which CPEC is assessed is that SSC should espouse accountability and transparency. It is argued that there must be sufficient data management and reporting channels (Indicator 13) as well as M\&E systems (Indicator 14) so that different phases of the project cycle are properly evaluated against the project goals and targets. Another key feature is that SSC providers (as well as receivers) need to be transparent regarding the sharing of data and information about the terms and conditions of financing (Indicator 15), and that such information must be accessible to civil society organisations, parliament, academia, and the media. Increased transparency regarding how SSC is provided and who the key decision-makers are would make the main stakeholders more responsible and accountable (Indicator 16). Thus, for enhanced reciprocal accountability and win-win situations, transparency is vital. 
In relation to this dimension and associated indicators, some initiatives have been taken. There are interactive websites that share a significant amount of information about projects in various sectors as well as about the companies and organisations involved. For example, most information about the ongoing projects and those completed-or nearing completion-are given on the website of the CPEC secretariat, a dedicated government unit in the Ministry of PDR. The website also contains the geographical location of CPEC projects as well as their estimated costs and completion dates. Additionally, there is the CPEC Portal, which is jointly managed by the Pakistan-China Institute, a private think tank based in Islamabad, and China Radio International, China's state-level radio and television media organisation specialising in international communications (The CPEC Portal, 2017). This website also shares information, reports, media coverage, and events related to CPEC. In view of this, a former minister of PDR stated in an interview that nothing has been concealed regarding CPEC and all details are available on its website (Iqbal, 2017). This was also reiterated by various Pakistani and Chinese officials during interviews that CPEC projects are being implemented in a very transparent way and no data or information is kept secret.

Although the government has tried to come up with information-sharing mechanisms, there is still considerable scepticism about the general transparency of CPEC projects. There have been various critical op-eds in print media stating that the financial mechanism of CPEC is quite opaque, as the government has never shared any official policy document in this regard (Husain, 2017; Hussain, 2017; Isran, 2017; Khan and Hyder, 2017; Saleem, 2017b; Zaidi, 2017). Similar opinions were expressed by several academics during my field visit. Although government functionaries claim that everything is transparent and no information has been kept secret, there are perceptions in the media that the government has been hiding the terms and conditions of Chinese investment and concessional loans. For example, Pakistani and Chinese officials who were interviewed stated that the interest rate is 2-3 per cent (personal communication, September 2017). However, a request to an official in the Ministry of PDR for a copy of a memorandum of understanding $(\mathrm{MoU})$ or agreement was not entertained, and it was stated that state-tostate agreements are exempt from the Right to Information Act (personal communication, September 2017). Although there is significant anecdotal information from various quarters, the fact remains that the government has not issued any policy document that specifically mentions Pakistan-China MoUs or agreements, nor the terms and conditions of development projects under CPEC. ${ }^{2}$

In view of this, it can be stated that there is a detailed step-by-step process in which different aspects of all CPEC projects are regularly reviewed by various groups and committees. It is too early to judge the efficacy of the process, as the real impacts of CPEC projects can only be evaluated once they are fully implemented. However, the presence of such mechanisms for decisionmaking and reviewing progress indicates that both sides have come up with 
appropriate measures to ensure reciprocal accountability for projects that are closely monitored not only by the independent media in Pakistan, but also by a number of international organisations.

\subsubsection{Development Efficiency and the Role of CPEC}

The fifth aspect of the SSC analytical framework is about its effectiveness in achieving development targets. There are four indicators to measure this dimension. Here, CPEC is assessed together in the light of flexibility and adaptation to local contexts (Indicator 17) and time and cost efficiency (Indicator 18). It is followed by a discussion of the two final indicators of SSC, including internal and external coordination and complementarity (Indicator 19) and policy coherence for development (Indicator 20) and how CPEC can be analysed according to these features.

Assessed in the light of "development effectiveness" and associated indicators, there are positive prospects associated with CPEC projects regarding power generation, creation of employment opportunities, and infrastructure upgradation. If viewed within the framework of specific indicators and principles such as time and cost efficiency, for example, an official in the Ministry of PDR stated that a coal-fired project in Sahiwal, Punjab-with a capacity of $1320 \mathrm{MW}$ and costing $\$ 1.6$ billion-was completed six months ahead of schedule (personal communication, September 2017). The official also stated that utilising cheap local labour and resources made this project more feasible and cost-efficient. In terms of its overall development impact, there is a broad consensus in Pakistan that CPEC is a win-win project for the entire region, as it will lead to greater regional connectivity and lower transport and communication costs. For instance, an aggregate of $\$ 11$ billion has been allocated for numerous communication and transport projects along the CPEC route to connect China with the Indian Ocean via the Gwadar Port that will also increase interprovincial connectivity across Pakistan. The lack of efficient transport and communication networks cost the country's economy 4-6 per cent of GDP annually (Government of Pakistan, 2014). To overcome this, Vision 2025 aims to "ensure reduction in transportation costs, safety in mobility, effective connectivity between rural areas and markets/urban centres, inter-provincial high-speed connectivity" and to establish high-capacity transport corridors connecting major regional trading partners (Government of Pakistan, 2014, p. 86). Thus, if properly implemented, CPEC projects could bring significant socio-economic benefits for both countries.

In relation to internal and external coordination (Indicator 19), both countries have established various coordination mechanisms in the form of the JCC and JWGs. In these working groups and committee, both Pakistani and Chinese officials and experts from several areas discuss all CPEC-related plans and policies.

With regard to policy coherence for development (Indicator 20), the two countries have been enjoying strong diplomatic and military ties for decades. 
However, trade and economic relations between the two countries were weak but intensified after the signing of the Free Trade Agreement (FTA) in 2006. Similarly, after the official launch of CPEC in 2015, multidimensional ties between the two countries have expanded significantly. An official in the Embassy of China stated that CPEC has accelerated cooperation between the two countries in other fields as well, especially in the education sector, as China is granting scholarships to hundreds of Pakistani students (personal communication, September 2017). The official also stated that there are about 22,000 Pakistani students in China. While all these are encouraging signs for greater people-to-people contact, research also shows that Pakistan has not benefited much from the FTA. According to Malik (2017), although bilateral trade has increased overall from about $\$ 85$ million in 1952 to $\$ 17$ billion in 2014, Pakistan's trade deficit has increased significantly, reaching \$12 billion in 2014. The author argues that, along with other factors, one of the reasons for this huge trade deficit is that exporters from other regions and countries such as ASEAN, Australia, and New Zealand are offered more preferential treatment under the FTA than Pakistani businessmen and exporters (Malik, 2017). In view of this-and for greater policy coherence for development-it can be validly argued that Pakistani traders and exporters need to be provided the same set of concessions in Chinese markets as are provided to exporters from other countries that have FTAs with China. If that were the case, Pakistani businesspersons could compete on a level playing field, and there would be more exports and subsequent development at the country level.

Overall, there are positive developmental prospects from CPEC for Pakistan, but there is also some scepticism. According to government policy documents, "the country's outlook is brightened and looks promising on the back of agricultural recovery, rebound in industrial activities and inflow of investment under CPEC" (Government of Pakistan, 2017, p. vi). On account of early harvest CPEC projects, Pakistan expects that overall economic growth will substantially increase from the current rate of 5-6 per cent to "over 8 per cent between 2018 and 2025" (Government of Pakistan, 2014, p. 44). Thus, CPEC holds considerable potential for the development of the region in the context of regional connectivity, diverse investment opportunities, industrial cooperation, financial cooperation, tourism, people-to-people contact, and livelihood opportunities.

In Pakistan, however, there are somewhat divided opinions about the role of CPEC and its development effectiveness. Some economists and analysts have argued that CPEC would provide more benefits to China than to Pakistan (Ahmad, 2017; Isran, 2017; Saleem, 2017b). There is a perception that Pakistan will bear much of the environmental, social, and economic cost, whereas the corridor and allied infrastructure facilities will be used by China, primarily for its own exports and imports, with few trickle-down effects for the local population (Khan and Hyder, 2017). 
There have been positive indicators offered by international organisations regarding CPEC, not only for Pakistan but for the whole region. If successfully implemented, the economic potential is significant for Pakistan and its neighbouring countries. In its report on Pakistan's economy, the International Monetary Fund mentioned the potential impact of CPEC. The report states that the economy is "benefitting from rising investment related to CPEC [... $]$ over the medium term, growth is expected to increase to about 6 per cent on the back of CPEC and other energy sector investments" (International Monetary Fund [IMF], 2017, p. 7). However, the report also cautioned that "over the medium-term, external payment obligations from CPEC-related investments would lead to a reduction in foreign reserves coverage, underscoring the need to foster a strong and sustained pick-up in exports" (IMF, 2017, p. 23). Hence, while CPEC-related investments are expected to resolve the chronic problem of energy deficiency and upgrade transport and communication infrastructure, it is essential to establish policies and plans to maximise its benefits for people and to minimise its long-term undesirable social, environmental, and economic implications.

\subsection{CONCLUSION}

Based on the findings concerning Chinese-funded projects in the light of SSC principles, this chapter argues that the China-Pakistan development partnership under CPEC is an example of SSC. For example, CPEC is a blend of investments and concessional loans obtained by Chinese companies from Chinese banks for implementing projects in Pakistan. In this way, the financial instrument is not purely developmental, nor does it come as aid in the form of a grant, but there seems to be a mutual belief that it is a win-win situation. The findings are summarised in Table 13.2, as per the five main dimensions of the analytical framework.

To a large extent, elements of the SSC and Chinese foreign aid policycomprising mutual respect, equality, fulfilling promises, building local capacity, and addressing actual needs_-are adhered to in the context of CPEC projects. Findings show that decisions about inclusion and the approval of projects under CPEC are taken by the JCC and JWGs, thereby ensuring domestic ownership. Also, projects have been undertaken in specific areas to address the pressing needs of the country, including energy, infrastructure upgradation, and industrialisation. Initiatives are underway that aim to transfer skills, knowledge, and technology, which could help with long-term capacity-building and self-sustained economic development.

At the same time, there are certain issues with projects under the CPEC umbrella. For example, although considerable anecdotal information is available, there is still a significant lack of transparency and a dearth of data regarding the terms and conditions of Chinese investments and concessional loans as well as future sharing of the revenues from tolls and levies. Similarly, 


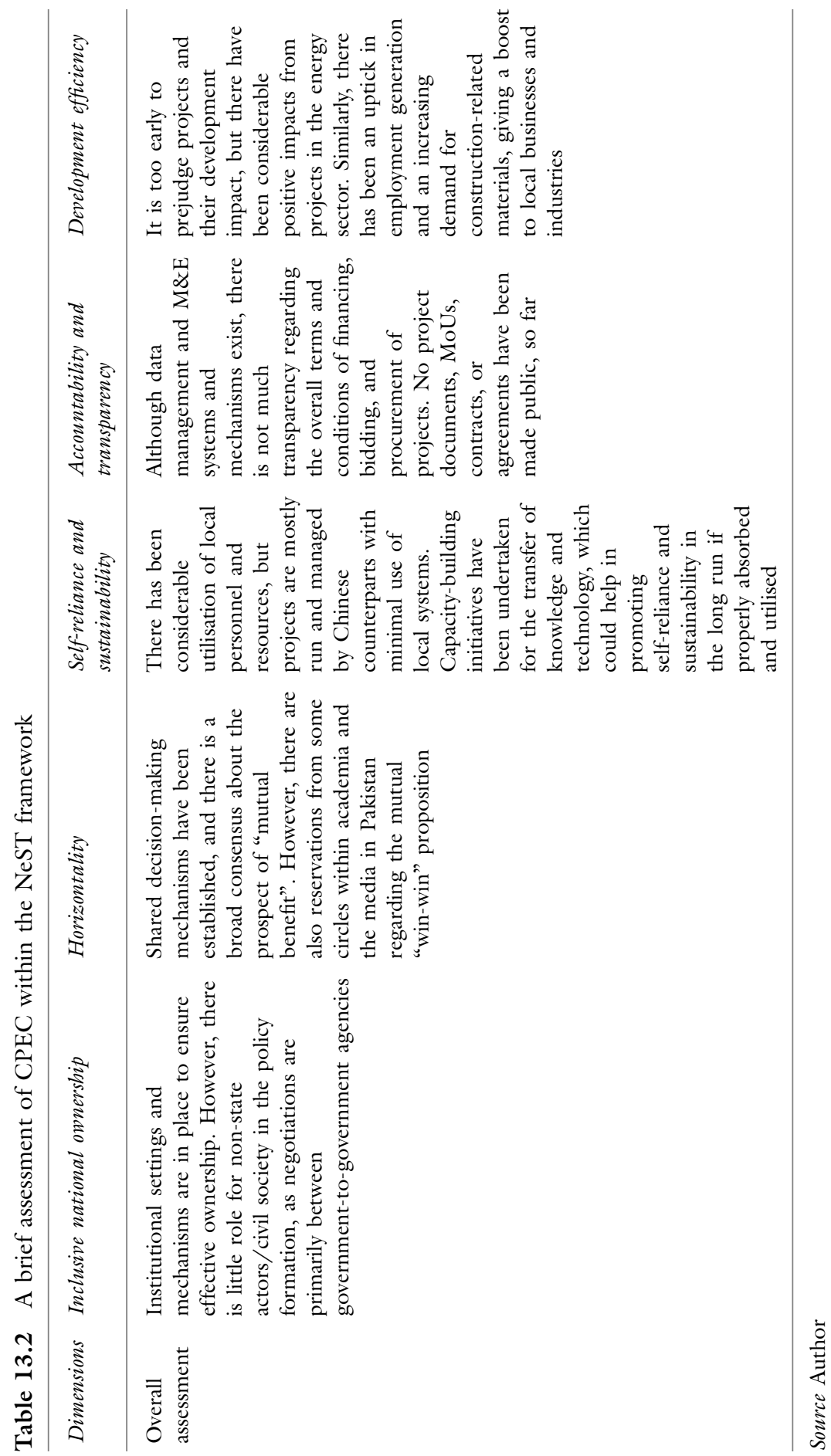


almost all the projects are being implemented by Chinese companies and stateowned enterprises without any competitive bidding. Thus, although there is no official document to confirm or deny it, there seems to be an understanding between the two governments that, in almost all projects, Chinese companies will implement projects without any external bidding. Considering this, it becomes clear that, although both governments have taken various initiatives and established platforms for joint decision-making and evaluation, there are still some issues, such as a lack of transparency and a prevalence of tied aid, in the CPEC financing mechanism.

Thus, it can be concluded that, as per the five broad dimensions of the SSC analytical framework, the China-Pakistan development partnership under CPEC has been doing well in the four areas of inclusive national ownership, horizontality, self-reliance and sustainability, and development effectiveness, but has lagged in accountability and transparency.

\section{Notes}

1. There is a perception among some members of the NeST that the SSC analytical framework has been developed by the South Africa (SA) chapter of NeST and therefore it is more appropriate to call it NeST SA or NSA framework. However, as the framework and its parameters and indicators have been taken from the study cited as NeST and not NSA, this study also uses NeST instead of NSA. Also, both in the NeST framework as well as in the Pakistani context, inclusive ownership is meant to include diverse government stakeholders, but there is no mention of private-sector actors. This work was supported by the Alexander von Humboldt Foundation under Grant No. 3.5 - 1162883 - PAK GFHERMES-P.

2. The only document that has been released so far is the much-awaited "Long Term Plan for China-Pakistan Economic Corridor (2017-2030)", which was approved by both governments during the 7th JCC meeting held in Islamabad in November 2017. The policy document outlines CPEC's vision and key goals as well as its guidelines and basic principles of cooperation. The Long-Term Plan (LTP) lists seven major areas of focus: connectivity, energy, trade and industrial parks, agricultural development and poverty alleviation, tourism, cooperation in areas concerning people's livelihoods, and non-governmental exchanges and financial cooperation (Government of Pakistan and People's Republic of China, 2017). Overall, the LTP neither provides new information about CPEC nor assuages the concerns of critics.

\section{REFERENCES}

Ahmad, S. I. (2017, September 3). CPEC is not a game-changer, it's game over. The News on Sunday. http://tns.thenews.com.pk/cpec-game-changer-game/.

Ali, G. (2017). China-Pakistan relations: A historical analysis. Karachi: Oxford University Press. 
Besharati, N. A., Rawhani, C., \& Rios, O. R. (2017). A monitoring and evaluation framework for South-South cooperation (Working Paper). Johannesburg: South African Institute of International Affairs.

Board of Investment. (2017). CPEC toll income to be thrice the budget of Pakistan. http://boi.gov.pk/ViewNews.aspx?NID=\%201766.

CPEC Secretariat. (2017). Updated energy projects. http://cpec.gov.pk/energy.

Government of Pakistan. (2014). Pakistan 2025: One nation one vision. Islamabad: Ministry of Planning, Development and Reform.

Government of Pakistan. (2017). Pakistan economic survey 2016-17. Islamabad: Ministry of Finance.

Government of Pakistan. (2018). Pakistan economic survey 2017-18. Islamabad: Ministry of Finance.

Government of Pakistan, \& People's Republic of China. (2017). Long-term plan for China-Pakistan economic corridor (2017-2030). Islamabad: Ministry of Planning, Development and Reform \& People's Republic of China: National Development \& Reform Commission.

Haider, M. (2017, November 28). Pakistan to get 9pc of Gwadar income, 15pc of FEZ: China. The News International. https://www.thenews.com.pk/print/249 957-pakistan-to-get-9pc-of-gwadar-income-15pc-of-fez-china.

Husain, K. (2017, May 15). Exclusive: CPEC master plan revealed. Dawn. https:// www.dawn.com/news/1333101.

Hussain, A. (2017, October 10). An open debate. The News International. https:// www.thenews.com.pk/print/235858-An-open-debate.

Hussain, S. R. (2016). Sino-Pakistan ties: Trust, cooperation and consolidation. In T. Fingar (Ed.), The new great game: China and South and Central Asia in the era of reform (pp. 116-146). Stanford, CA: Stanford University Press.

IMF (International Monetary Fund). (2017). Pakistan (IMF Country Report No. 16/325). Washington, DC: Author.

Iqbal, A. (2017, May 17). CPEC most transparent project of Pakistan, says Ahsan Iqbal. Pakistan Today. https://profit.pakistantoday.com.pk/2017/05/17/ cpec-most-transparent-project-of-pakistan-says-ahsan-iqbal/.

Isran, M. A. (2017, January 27). Six concerns PML-N government must address about CPEC. The Express Tribune. https://tribune.com.pk/story/1308699/sixconcerns-pml-n-government-must-address-cpec/.

Khan, M., \& Hyder, D. (2017, January 11). CPEC: The devil is not in the details. Herald. https://herald.dawn.com/news/1153597.

Khawar, H. (2017, October 26). CPEC toll income-Myth and reality. The Express Tribune. https://tribune.com.pk/story/1541404/6-cpec-toll-incomemyth-reality/.

Kreft, S., Eckstein, D., \& Melchior, I. (2017). Global climate risk index 2017: Who suffers most from extreme weather events? Weather-related loss events in 2015 and 1996 to 2015. Berlin: Germanwatch.

Malik, A. R. (2017). The Pakistan-China bilateral trade: The future trajectory. Strategic Studies, 37(1), 66-89.

Mustafa, K. (2018, May 9). Cost of CPEC coal power projects per MW 40pc higher. The News International. https://www.thenews.com.pk/print/314412-cost-of-cpeccoal-power-projects-per-mw-40pc-higher. 
OECD (Organisation for Economic Co-operation and Development). (2016). Development co-operation report 2016: The Sustainable Development Goals as business opportunities. Paris: Author.

People's Republic of China. (2014). China's foreign aid (2014). Beijing: Information Office of the State Council.

Saleem, F. (2017a, March 26). Coal power. The News International. https://www. thenews.com.pk/print/194527-Coal-power.

Saleem, F. (2017b, February 19). CPEC. The News International. https://www.the news.com.pk/print/235350-CPEC.

Small, A. (2015). The China-Pakistan axis: Asia's new geopolitics. New York, NY: Oxford University Press.

The CPEC Portal. (2017). The CPEC portal. http://www.cpecinfo.com/pci-cpec-fou nder.

United Nations Economic and Social Commission for Asia and the Pacific. (2017). The Belt and Road Initiative and the role of ESCAP. New York, NY: United Nations.

UNGA (United Nations General Assembly). (2015). Transforming our world: The 2030 Agenda for Sustainable Development. New York, NY: United Nations.

World Bank. (2015). From billions to trillions: Transforming development finance post2015. Washington, DC: Author.

Zaidi, S. A. (2017, June 18). Has China taken over Pakistan? The News on Sunday. http://tns.thenews.com.pk/china-taken-pakistan-cpec/.

Zaman, M. H. (2016, December 27). Environment: Not for sale. The Express Tribune. http://tribune.com.pk/story/1276746/environment-not-sale/.

Open Access This chapter is licensed under the terms of the Creative Commons Attribution 4.0 International License (http://creativecommons.org/licenses/by/4.0/), which permits use, sharing, adaptation, distribution and reproduction in any medium or format, as long as you give appropriate credit to the original author(s) and the source, provide a link to the Creative Commons license and indicate if changes were made.

The images or other third party material in this chapter are included in the chapter's Creative Commons license, unless indicated otherwise in a credit line to the material. If material is not included in the chapter's Creative Commons license and your intended use is not permitted by statutory regulation or exceeds the permitted use, you will need to obtain permission directly from the copyright holder.

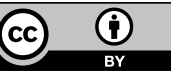

